\title{
Competição entre feijoeiros e Plantas daninhas em Função do Tipo de CRescimento dos Cultivares ${ }^{1}$
}

\author{
Competition Between the Common Bean and Weed in Function of Cultivar Growth Type
}

TEIXEIRA, I.R. ${ }^{2}$, SILVA, R.P. ${ }^{3}$, SILVA, A.G. ${ }^{4}$ e FREITAS, R.S. ${ }^{5}$

\begin{abstract}
RESUMO - Objetivou-se com este trabalho avaliar a capacidade competitiva de genótipos de feijão de diferentes tipos de crescimento sob presença e ausência de comunidade infestante de plantas daninhas, em duas safras de cultivo ("águas" de 2006/07 e "seca" de 2007). Foi utilizado o delineamento de blocos casualizados, em esquema fatorial $3 \times 2$, com quatro repetições. Os tratamentos foram constituídos de três cultivares de feijão com diferentes tipos de crescimento (Pérola: tipo III/II; Aporé: tipo III; e BRS Radiante: tipo I), em combinação com dois tipos de manejo de plantas daninhas: área capinada manualmente e área não capinada. Conclui-se que no cerrado brasileiro, na safra das "águas", os problemas da cultura do feijão com as plantas daninhas foram agravados, especialmente com Brachiaria ssp., Cenchrus echinatus, Digitaria horizontalis e Eleusine indica. Os cultivares de feijão com hábitos de crescimento semiereto (Pérola) e prostrado (Aporé) foram mais competitivos com a comunidade infestante de plantas daninhas.
\end{abstract}

Palavras-chave: Phaseolus vulgaris, tipo de crescimento, matocompetição, rendimento.

ABSTRACT - This work aimed to evaluate the competitive capacity of common bean cultivars of different growth types under the presence and absence of weed species communities during two crop seasons(rainy 2006/2007 and dry 2007). The experiment was arranged in a randomized block design, in a factorial scheme with four replications. The treatments consisted of three bean cultivars with different type of growth ("Pérola": type III/II, "Aporé": type III and "BRS Radiante": type I) in combination with two types of management of weed species: cultivated with and without weed. It was concluded that in the "cerrado" during the rainy season, the problems of the common bean with the weed species aggravated, especially in relation to Brachiaria ssp., Cenchrus echinatus, Digitaria horizontalis and Eleusine indica. The common bean genotypes with semi-erect ("Pérola") and prostrated ("Aporé) growth habits were more competitive against the weed plant community.

Keywords: Phaseolus vulgaris, type the growth, weed competition, yield.

\section{INTRODUÇÃO}

O feijão, juntamente com o arroz, constitui um dos alimentos mais importantes da população brasileira, sobretudo nas classes de menor poder aquisitivo. O Brasil destaca-se atualmente como maior produtor mundial de feijão comum (Phaseolus vulgaris), com produção estimada em 3,2 milhões de toneladas e produtividade média em torno de $815 \mathrm{~kg} \mathrm{ha}^{-1}$ na safra 2006/2007 (CONAB, 2008), valor este que pode ser considerado baixo, uma vez que

1 Recebido para publicação em 6.2.2008 e na forma revisada em 5.6.2009.

2 Professor da Universidade Estadual de Goiás - UnU Ipameri, Rodovia GO 330, Km 241, Anel Viário, $74750-150$ Ipameri-GO, <itamar.texeira@ueg.br>; ${ }^{3}$ Mestrando do Curso de Engenharia Agrícola da Universidade Estadual de Goiás - UnUCET; ${ }^{4}$ Professor da Fesurv - Universidade de Rio Verde, Caixa Postal 104, Campus Universitário, Fazenda Fonte do Saber, 75901-970 Rio Verde-GO; ${ }^{5}$ Pesquisador da Apta - Votuporanga, Estrada Municipal Votuporanga - Floreal, Km 4 + 6 (terra) Zona Rural, Caixa Postal 61, 15500-000 Votuporanga-SP. 
em lavouras onde se emprega alto nivel tecnológico têm sido obtidos valores três vezes superiores.

Uma série de fatores é responsável pela baixa produtividade, entre os quais se destaca a interferência imposta pelas plantas daninhas. O feijoeiro, por ser de baixa capacidade competitiva e enquadrado no grupo de culturas que menos sombreiam o solo, sofre intensa interferência das plantas daninhas, resultando em sérios prejuízos no crescimento, na produtividade e na operacionalização de colheita. Dependendo de fatores relacionados à cultura e à comunidade infestante e, ainda, de fatores ambientais, as perdas na produtividade ocasionadas pela interferência das plantas daninhas na cultura do feijão podem atingir 67\% (Salgado et al., 2007). Essa redução é ocasionada principalmente pela competição por água, luz e nutrientes (Cobucci, 2004).

No que diz respeito à capacidade de competição de planta de feijão, pode-se dizer que a morfologia da planta é fator preponderante, em que os genótipos de hábitos de crescimento dos tipos I e II, com porte ereto e poucos ramificados, são menos competitivos. Por outro lado, os genótipos tipo III, os mais cultivados, promovem maior cobertura do solo (Santos \& Gavilanes, 2006). Em trabalho conduzido no Estado do Paraná por Farias \& Kranz (1982), o cv. Carioca - tipo III foi mais produtivo que Goiano Precoce - tipo I e Aroana - tipo II. Isso se deu, segundo os autores, em virtude do hábito/tipo da planta, que, no caso do Carioca, promoveu maior cobertura do solo comparativamente aos outros dois cultivares. Resultado semelhante foi obtido por Andrade et al. (1999) também no Paraná, ao investigarem o efeito competidor dos cultivares de feijão Aporé, IAPAR 14 e Pérola em diferentes espaçamentos com e sem capina. Esses autores constataram que nos tratamentos não-capinados os cultivares Aporé e IAPAR 14, classificados como semiprostrados (tipo III), foram mais produtivos quando cultivados nos menores espaçamentos, comparativamente ao cultivar Pérola semiereto (tipo III/II).

Em regiões como o cerrado, onde as condições climáticas são bem definidas, o feijoeiro é cultivado em três épocas: "águas", "seca" e "outono-inverno", tendo na primeira safra predominado os maiores problemas com plantas daninhas, em razão, especialmente, da boa disponibilidade hídrica associada à intensa radiação solar, que favorece a infestação de plantas daninhas com metabolismo C-4, como: braquiárias (Brachiaria spp.), capimcarrapicho (Cenchrus echinatus), grama-seda (Cynodon dactylon), capim-colonião (Panicum maximum), capim-pé-de-galinha (Eleusine indica), capim-favorito (Digitaria horizontalis), tiririca (Cyperus rotundus) (Ferreira et al., 1994, 2006; Cobucci, 2004). Por outro lado, na safra da "seca" e de "outono-inverno" esses problemas são pormenorizados, devido à menor influência dos fatores do meio (disponibilidade hídrica e radiação solar) sobre a comunidade infestante, o que acaba por favorecer o desenvolvimento das plantas da feijão, aumentando assim seu potencial competitivo.

Trabalhos investigativos sobre comportamento de genótipos de feijão de diferentes tipos de crescimento sob competição intensa com plantas daninhas - nas diferentes épocas de cultivo e condições de solo e clima - em condições de cerrado são incipientes. Nesse contexto, este trabalho teve como objetivo averiguar, em duas safras de cultivo de feijão, o comportamento de genótipos de feijão de diferentes tipos de crescimento sob competição com plantas daninhas, em áreas com expressiva cobertura vegetal, nas condições edafoclimáticas do cerrado goiano.

\section{MATERIAL E MÉTODOS}

Os experimentos foram conduzidos numa mesma área experimental, pertencente à Universidade Estadual de Goiás-GO, em Ipameri-GO, nas safras das "águas" de 2006/ 2007 e "seca" de 2007. As coordenadas geográficas da área experimental são: $17^{\circ} 43^{\prime} 19^{\prime \prime} \mathrm{S}$, $48^{\circ} 09^{\prime} 35^{\prime \prime} \mathrm{W}$ e altitude de $820 \mathrm{~m}$. O clima regional é classificado como Cwa-Mesotérmico Úmido, com precipitação e temperatura média anual de $1.750 \mathrm{~mm}$ e $25^{\circ} \mathrm{C}$, respectivamente (SEPLAN, 2007).

O solo onde foram realizados os experimentos foi classificado como Latossolo Vermelho-Amarelo distroférrico. Foi coletada uma amostra de solo na camada de $0-20 \mathrm{~cm}$, na qual efetuaram-se análises químicas e fisicas, cujos resultados foram: $\mathrm{pH}\left(\mathrm{H}_{2} \mathrm{O}\right)$ 6,3; $\mathrm{P}\left(\mathrm{mg} \mathrm{dm}^{-3}\right), 2,1 ; \mathrm{K}\left(\mathrm{mg} \mathrm{dm}^{-3}\right), 62 ; \mathrm{Ca}\left(\mathrm{cmol} \mathrm{dm}^{-3}\right)$, 
4,2; $\mathrm{Mg}\left(\mathrm{cmol} \mathrm{dm}^{-3}\right), 1,5 ; \mathrm{Al}\left(\mathrm{cmol} \mathrm{dm}^{-3}\right), 0,0$; $\mathrm{H}+\mathrm{A} 1\left(\mathrm{cmol} \mathrm{dm}^{-3}\right), 1,9 ; \mathrm{m}(\%) 0,0 ; \mathrm{V}(\%), 63$; $\mathrm{B}\left(\mathrm{mg} \mathrm{dm}^{-3}\right), 0,6 ; \mathrm{Cu}\left(\mathrm{mg} \mathrm{dm}^{-3}\right), 1,7 ; \mathrm{Fe}\left(\mathrm{mg} \mathrm{dm}^{-3}\right)$, 35,0; $\mathrm{Mn}\left(\mathrm{mg} \mathrm{dm}^{-3}\right), 9,2 ; \mathrm{Zn}\left(\mathrm{mg} \mathrm{dm}^{-3}\right), 2,3$; matéria orgânica $=2,5 \mathrm{dag} \mathrm{kg}^{-1}$; areia $=350 \mathrm{~g} \mathrm{~kg}^{-1}$; silte $=25 \mathrm{~g} \mathrm{~kg}^{-1} ; \mathrm{e}$ argila $=165 \mathrm{~g} \mathrm{~kg}^{-1}$.

Foi empregado o delineamento de blocos casualizados, em esquema fatorial $3 \times 2$, com quatro repetições. Os tratamentos envolveram três cultivares de feijão com diferentes tipos de crescimento (Pérola = tipo III /II; Aporé $=$ tipo III; e BRS Radiante = tipo I), combinados com dois tipos de manejo de plantas daninhas: área capinada manualmente (sem infestação de plantas daninhas por todo o ciclo dos cultivares) e área não-capinada (com infestação de plantas daninhas por todo o ciclo dos cultivares). As capinas foram realizadas a cada 15 dias, até o completo fechamento da lavoura.

O cultivar Pérola possui grão tipo carioca, peso médio de 100 sementes de 23-25 g, hábito de crescimento indeterminado III/II, porte semiereto a prostrado, ciclo normal; é resistente a mancha-angular, ferrugem e mosaico comum. O cultivar Aporé tem grão tipo carioca, com halo amarelo, peso médio de cem sementes de 23-25 g, hábito de crescimento indeterminado III, porte prostrado, ciclo normal, sendo resistente a mancha-angular, mosaico comum e algumas raças de antracnose. A BRS Radiante possui grão do tipo manteigão, de coloração rajada, peso médio de cem sementes de 44-45 g, hábito de crescimento determinado I, porte ereto, ciclo precoce e resistente a ferrugem, mosaico comum e algumas raças de antracnose e tem reação intermediária à mancha-angular (Ramalho \& Abreu, 2006).

As parcelas foram constituídas de quatro fileiras de 5,0 $\mathrm{m}$ de comprimento, espaçadas de $0,50 \mathrm{~m}$, sendo utilizadas as duas linhas centrais como área útil, eliminando-se $0,50 \mathrm{~m}$ de cada lado, a título de bordadura.

Nos dois experimentos, o preparo do solo constituiu-se de uma aração e duas gradagens. Empregou-se na adubação básica dos dois experimentos o formulado 05-25-20 na dose de $400 \mathrm{~kg} \mathrm{ha}^{-1}$. Foi usada a densidade de semeadura de 12 plantas por metro linear. Aos 25 dias de emergência da cultura (DAE), foi feita adubação de $\mathrm{N}$ em cobertura na dose de $40 \mathrm{~kg} \mathrm{ha}^{-1}$, tendo ureia como fonte.
Nas safras das "águas" e "seca" observouse infestação de cigarrinha-verde (Empoasca kraemeri) e vaquinha (Diabrotica speciosa), controladas aos $18 \mathrm{DAE}$ com uma aplicação do produto comercial Decis $25 \mathrm{CE}$, na dose de $300 \mathrm{~mL}$ ha $^{-1}$. Com relação às doenças, notaramse baixo níveis de infestação nas duas épocas em questão, dispensando assim qualquer controle. Os demais tratos culturais foram os normalmente aplicados na cultura.

A avaliação da infestação de plantas daninhas, na área da parcela não-capinada, foi realizada quando a lavoura estava com $30 \mathrm{DAE}$ e constou da utilização de um quadrado de $0,25 \mathrm{~m}^{2}$, lançado duas vezes, aleatoriamente, em cada parcela. Posteriormente, fez-se a identificação das espécies daninhas delimitadas pelo quadrado. Concluído este procedimento, as plantas de feijão foram colocadas em sacos de papel e levadas ao laboratório, onde foram mantidas em estufa a $72{ }^{\circ} \mathrm{C}$ até atingirem peso constante. Posteriormente, quantificou-se a massa seca de cada tratamento.

Aos 55 DAE, foi avaliada visualmente - por escala de notas, atribuindo notas de zero (solo descoberto) até 100 (solo totalmente coberto) a porcentagem de cobertura do solo pelas plantas daninhas. As plantas da área útil das parcelas foram colhidas e trilhadas para determinação do rendimento de grãos, levando-se em consideração $13 \%$ de umidade. Determinaram-se também os componentes do rendimento de grãos (número de vagens por plantas, número de grãos por vagem e peso de 100 grãos) a partir de 10 plantas da área útil das parcelas.

Os dados foram submetidos à análise de variância; quando detectadas diferenças significativas entre os tratamentos, as médias foram comparadas pelo teste de Tukey a $5 \%$ de probabilidade.

\section{RESULTADOS E DISCUSSÃO}

\section{Infestação de plantas daninhas}

Na safra das "águas", notou-se, de modo geral, que houve maiores problemas com a comunidade infestante de plantas daninhas, comparativamente à safra da "seca", com predominância de gramíneas como: braquiárias, capim-carrapicho, capim-marmelada (Brachiaria plantaginea), capim-colchão e 
capim-pé-de-galinha. Por outro lado, folhas largas, como mentrasto (Ageratrum conyzoides), caruru (Amaranthus spp.), leiteiro (Euphorbia heterophyla), trapoeraba (Commelina benghalensis), picão-preto (Bidens pilosa) e joáde-capote (Solanum spp.), predominaram na safra da "seca". Essa diferenciação no aparecimento das espécies nas duas épocas de cultivo era esperada, uma vez que na safra das "águas" as gramíneas (folhas estreitas) são dominantes nas áreas de cultivo, em razão de serem plantas C-4, exigindo para isso alta intensidade luminosa associda à maior disponibilidade hídrica. Em contrapartida, na "seca", a menor intensidade luminosa favorece o aparecimento das plantas daninhas $\mathrm{C}-3$ (folhas largas) (Ferreira et al., 1994, 2006; Cobucci, 2004).

Tanto nas safra das "águas" como da "seca" os problemas de competição com plantas daninhas foram maiores no cv. BRS Radiante, conforme constatado das avaliações de plantas daninhas referentes à produção de massa seca (Figura 1) e as taxas de cobertura promovidas por elas (Figura 2). Esses resultados corroboram as afirmações de Farias \& Kranz (1982) e Andrade et al. (1999), de que os cultivares do tipo I, a exemplo do cv. BRS Radiante, apresentam menor potencial competitivo com as plantas daninhas devido ao porte ereto associado ao menor número de ramificações, tendo, assim, dificuldade de promover a cobertura do solo. Por sua vez, os cultivares Aporé e Pérola - classificados, respectivamente, como tipo III e tipo III/II ramificam mais e cobrem melhor o solo, resultando em menor insfestação de plantas daninhas na área de cultivo.

Pelos resultados obtidos, torna-se evidente que a escolha de cultivares de feijão com maior potencial competitivo é uma prática simples, que pode ser usada pelos agricultores em sua lavoura para aprimorar o manejo das plantas invasoras nas áreas de cultivo, sem ocasionar nenhum custo adicional.

\section{Avaliação das características agronômicas}

Na safra das "águas", o rendimento e seus componentes (número de vagens por planta, número de grãos por vagem e peso de cem grãos) variaram em função dos cultivares testados, enquanto somente o rendimento mostrou-se influenciado pelo sistema de manejo de plantas daninhas. Na safra da "seca", observou-se comportamento semelhante tanto do rendimento como dos seus componentes, acrescido de significância do fator manejo de plantas daninhas para o peso de cem grãos. Não houve efeito significativo da interação cultivares $\mathrm{x}$ manejo de plantas daninhas.

O número de vagens por plantas esteve relacionado com o rendimento de grãos, sendo os cultivares Pérola e Aporé aqueles com maior número de vagens por planta e, portanto, maior rendimento de grãos nas safras das "águas" (Tabela 1). Esse comportamento é embasado no fato de os cultivares dos tipos III (Aporé) e III/II (Pérola) produzirem maior número de ramificações e, consequentemente, maior número de vagens por planta, proporcionando dessa forma maiores patamares de produtividade. Para a safra das "secas", o maior número de vagens por planta proporcionou maior rendimento de grãos somente no cultivar Pérola, em ambas as safras (Tabelas 1 e 2). A influência direta desse componente no rendimento foi constatada em outros resultados de pesquisa (Valério et al., 1999; Souza et al., 2003; Teixeira et al., 2004).

O número de grãos por vagem obtido com os cultivares Peróla e Aporé contribui para obtenção de maiores rendimentos de grãos nas safras da "água" e "seca" (Tabelas 1 e 2). Por outro lado, também em ambas as safras, na presença de maior número de grãos por vagens houve os menores pesos de cem grãos nos cultivares Pérola e Aporé.

O maior rendimento de grãos foi obtido na safra da "seca", podendo-se atribuir essa resposta à utilização de irrigação complementar associada à menor competição das plantas daninhas com o feijoeiro. Essas observações condizem com as afirmações de Araújo \& Ferreira (2006), de que nos cultivos de feijão da "seca" e de "outono-inverno" constatamse menores problemas fitossanitários, incluídos aqueles relacionados às plantas daninhas.

Quando se avalia o efeito do manejo das plantas daninhas nos componentes do rendimento do feijoeiro, constatou-se significância 
para o número de vagens por planta e peso de cem grãos na safra da "seca" (Tabela 2). Nessa situação, o manejo das plantas daninhas proporcionou maiores valores dessas
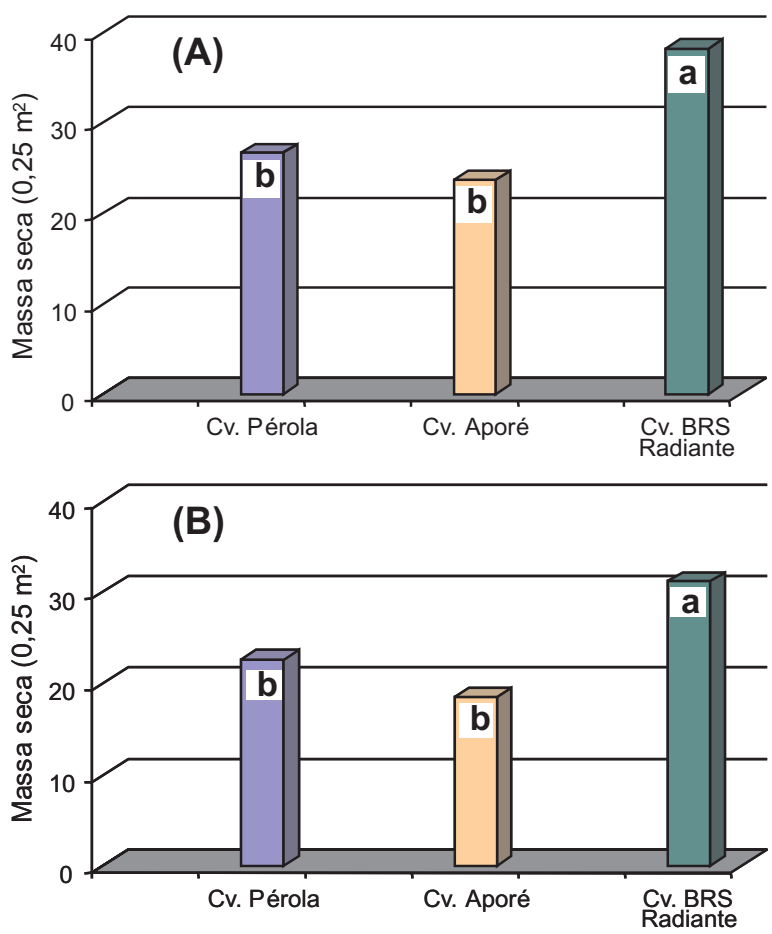

Figura 1 - Médias percentuais da produção de massa seca de plantas daninhas sob competição de genótipos de feijão na presença de plantas daninhas, nas safras das "águas" (A) e da "seca" (B). Médias seguidas pela mesma letra não diferem entre si pelo teste de Tukey a 5\% de probabilidade.

Tabela 1 - Características agronômicas de genótipos de feijão na presença e ausência de competição com plantas daninhas safra das "águas"

\begin{tabular}{|l|c|c|c|c|}
\hline \multirow{2}{*}{ Fator } & \multicolumn{4}{|c|}{ Característica } \\
\cline { 2 - 5 } & $\begin{array}{c}\text { Número de } \\
\text { vagens por } \\
\text { planta }\end{array}$ & $\begin{array}{c}\text { Número de } \\
\text { grãos por } \\
\text { vagens }\end{array}$ & $\begin{array}{c}\text { Peso de } \\
\text { cem grãos } \\
(\mathrm{g})\end{array}$ & $\begin{array}{c}\text { Rendimento } \\
\text { de grãos } \\
\left(\mathrm{kg} \mathrm{ha}^{-1}\right)\end{array}$ \\
\hline \multicolumn{5}{|c|}{ Cultivares } \\
\hline Pérola & $21,4 \mathrm{a}$ & $5,3 \mathrm{a}$ & $21,8 \mathrm{~b}$ & $1.582 \mathrm{a}$ \\
Aporé & $14,5 \mathrm{~b}$ & $5,3 \mathrm{a}$ & $21,2 \mathrm{~b}$ & $1.359 \mathrm{a}$ \\
BRS Radiante & $11,1 \mathrm{c}$ & $4,4 \mathrm{~b}$ & $34,3 \mathrm{a}$ & $1.156 \mathrm{~b}$ \\
\hline \multicolumn{5}{|c|}{ Manejo de plantas daninhas } \\
\hline Presente & 16,6 & 5,0 & 26,2 & $1.579 \mathrm{a}$ \\
Ausente & 14,8 & 5,0 & 25,4 & $1.152 \mathrm{~b}$ \\
Média & 15,7 & 5,0 & 25,8 & 1.365 \\
CV & 37,78 & 8,86 & 13,20 & 21,12 \\
\hline
\end{tabular}

Médias seguidas pela mesma letra não diferem entre si pelo teste Tukey a $5 \%$ de probabilidade. características, devido à ausência de competição com as plantas de feijão por fatores como água, luz e nutrientes, proporcionando, consequentemente, maior rendimento de grãos.
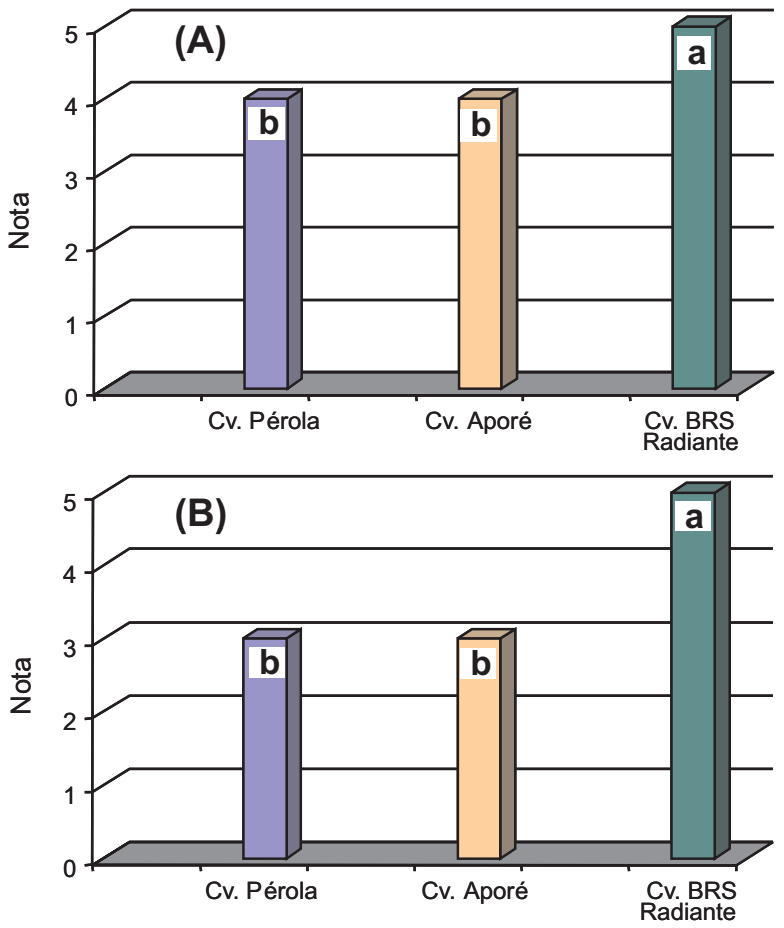

Figura 2 - Médias da avaliação visual da taxa de cobertura de plantas daninhas em área sob cultivo com diferentes genótipos de feijão na presença de plantas daninhas, nas safras das "águas" (A) e "seca" (B). Médias seguidas pela mesma letra não diferem entre si pelo teste de Tukey a $5 \%$ de probabilidade.

Tabela 2 - Características agronômicas de genótipos de feijão na presença e ausência de competição com plantas daninhas safra da "seca"

\begin{tabular}{|l|c|c|c|c|}
\hline \multirow{2}{*}{ Fator } & \multicolumn{4}{|c|}{ Característica } \\
\cline { 2 - 5 } & $\begin{array}{c}\text { Número de } \\
\text { vagens por } \\
\text { planta }\end{array}$ & $\begin{array}{c}\text { Número de } \\
\text { grãos por } \\
\text { vagens }\end{array}$ & $\begin{array}{c}\text { Peso de } \\
\text { cem grãos } \\
(\mathrm{g})\end{array}$ & $\begin{array}{c}\text { Rendimento } \\
\text { de grãos } \\
\left(\mathrm{kg} \mathrm{ha}^{-1}\right)\end{array}$ \\
\hline \multicolumn{5}{|c|}{ Cultivares } \\
\hline Pérola & $13,0 \mathrm{a}$ & $5,5 \mathrm{a}$ & $24,6 \mathrm{~b}$ & $2.072 \mathrm{a}$ \\
Aporé & $9,0 \mathrm{~b}$ & $5,5 \mathrm{a}$ & $22,8 \mathrm{~b}$ & $1.912 \mathrm{a}$ \\
BRS Radiante & $9,0 \mathrm{~b}$ & $4,3 \mathrm{~b}$ & $40,4 \mathrm{a}$ & $1.334 \mathrm{~b}$ \\
\hline \multicolumn{5}{|c|}{ Manejo de plantas daninhas } \\
\hline Presente & $13,4 \mathrm{a}$ & 5,2 & $32,1 \mathrm{a}$ & $2.344 \mathrm{a}$ \\
Ausente & $7,3 \mathrm{~b}$ & 5,0 & $26,5 \mathrm{~b}$ & $1.202 \mathrm{~b}$ \\
Média & 10,3 & 5,1 & 29,3 & 1.733 \\
CV & 15,01 & 9,94 & 21,36 & 20,63 \\
\hline
\end{tabular}

Médias seguidas pela mesma letra não diferem entre si pelo teste Tukey a $5 \%$ de probabilidade.

Planta Daninha, Viçosa-MG, v. 27, n. 2, p. 235-240, 2009 
Sob competição com plantas daninhas, observaram-se decréscimos de 27 e 49\% no rendimento de grãos de feijão, nas safras das "águas" e "seca", respectivamente. Esses resultados são inferiores aos $67 \%$ de redução na produtividade de grãos de feijão em competição com plantas daninhas em Jaboticabal-SP, o que pode ser justificado pelas diferentes condições edafoclimáticas existentes por ocasião da condução dos trabalhos.

Pela análise de todas as características avaliadas nas condições de cerrado, constatase que, na safra das "águas", os problemas com plantas daninhas em lavouras de feijão são agravados. Os cultivares de feijão Pérola (tipo II/III) e Aporé (tipo III) são mais competitivos com a comunidade infestante de plantas daninhas.

\section{LITERATURA CITADA}

ANDRADE, C. A. B. et al. Efeito da competição com plantas daninhas em diferentes espaçamentos sobre o rendimento de três cultivares de feijão (Phaseolus vulgaris L.) Ci. Agrotecnol., v. 23, n. 3, p. 529-539, 1999.

ARAÚJO, G. A. A.; FERREIRA, A. C. B. Manejo do solo e plantio. In: VIEIRA, C.; PAULA JÚNIOR, T.J.; BORÉM, A. Feijão. 2.ed. Viçosa, MG: Universidade Federal de Viçosa, 2006. p. $88-114$

COBUCCI, T. Manejo e controle de plantas daninhas em feijão. In: VARGAS, L.; ROMAN, E. S. Manual de manejo e controle de plantas daninhas. Bento Gonçalves: Embrapa Uva e Vinho, 2004. p. 453-480.

COMPANHIA NACIONAL DO ABASTECIMENTO CONAB. Safra de feijão total (1 ${ }^{\mathrm{a}}, 2^{\mathrm{a}}$ e $3^{\mathrm{a}}$ safra) - $3^{\mathrm{o}}$ levantamento. Brasília. Disponível em: $<$ http:www.conab.br>. Acesso em: 15 mar. 2008.
FARIAS, R. T.; KRANZ, W. N. Determinação de espaçamento e densidades adequados para as cultivares de diferentes portes. In: REUNIÃO NACIONAL DE PESQUISA DE FEIJÃO, 1., 1982, Goiânia. Anais... Goiânia: Embrapa-CNPAF, 1982. p. 18-19.

FERREIRA, F. A. et al. Manejo de plantas daninhas. In VIEIRA, C.; PAULA JÚNIOR, T. J.; BORÉM, A. Feijão. 2.ed. Viçosa, MG: Universidade Federal de Viçosa, 2006. p. 309-340.

FERREIRA, L. R; FERREIRA, F. A.; SILVA, J. F. Manejo integrado de plantas daninhas na cultura do feijão de outonoinverno. Inf. Agropec., v. 17, n. 178, p. 38-42, 1994.

RAMALHO, M. A. P.; ABREU, A. F. B. Cultivares. In: VIEIRA, C.; PAULA JÚNIOR, T. J.; BORÉM, A. (Eds.). Feijão. 2.ed. Viçosa, MG: Universidade Federal de Viçosa, 2006. p. $415-436$.

SANTOS, J. B.; GAVILANES, M. L. Botânica. In: VIEIRA, C.; PAULA JÚNIOR, T. J.; BORÉM, A. (Eds). Feijão. 2.ed. Viçosa, MG: Universidade Federal de Viçosa, 2006. p. 41-65.

SALGADO, T. P. et al. Interferência das plantas daninhas no feijoeiro carioca. Planta Daninha, v. 25, n. 3, p. 443-448, 2007.

SECRETARIA DE PLANEJAMENTO DO ESTADO DE GOIÁS - SEPLAN-GO. Coordenadas geográficas dos municípios. Disponível em: $<\mathrm{http} / / /$ portalsepin.seplan.go.gov.br/anuario/situaçãofisica/ tabela1.htm>. Acesso em: 25 ago. 2007

SOUZA, A. B.; ANDRADE, M. J. B.; MUNIZ, J. A. Altura de planta e componentes do rendimento do feijoeiro em função de população de plantas, adubação e calagem. Ci. Agrotecnol., v. 27, n. 6, p. 1205-1213, 2003.

TEIXEIRA, I. R. et al. Manganese and zinc leaf apllication on commom bean grown on a "cerrado" soil. Sci. Agric., v. 61, n. 1, p. $77-81,2004$

VALÉRIO, C. R.; ANDRADE, M. J. B.; FERREIRA, D. F. Comportamento das cultivares de feijão Aporé, Carioca e Pérola em diferentes populações de plantas e espaçamentos entre linhas. Ci. Agrotecnol., v. 23, n. 3, p. 515-528, 1999. 